\title{
Evaluation of in vivo efficacy of radiofrequency ablation with D-sorbitol in animal liver
}

\author{
ASAHIRO MORISHITA ${ }^{1}$, TEPPEI SAKAMOTO ${ }^{1}$, HIDEKI KOBARA ${ }^{1}$, TOMOKO TADOKORO ${ }^{1}$, \\ KYOKO OHURA $^{1}$, KOJI FUJITA ${ }^{1}$, JOJI TANI ${ }^{1}$, HISAAKI MIYOSHI ${ }^{1}$, HIROHITO YONEYAMA ${ }^{1}$, \\ TAKASHI HIMOTO ${ }^{2}$ and TSUTOMU MASAKI ${ }^{1}$ \\ ${ }^{1}$ Department of Gastroenterology and Neurology, Faculty of Medicine, Kagawa University, Takamatsu, Kagawa 761-0793; \\ ${ }^{2}$ Department of Medical Technology, Kagawa Prefectual University of Health Sciences, \\ Takamatsu, Kagawa 761-0123, Japan
}

Received May 22, 2015; Accepted August 12, 2015

DOI: $10.3892 / \mathrm{mco} .2015 .680$

\begin{abstract}
Percutaneous radiofrequency ablation (RFA) enables cauterization of liver cancer in a limited number of sessions without major complications. In contrast to the efficacy of this technique, the size of coagulation necrosis is limited due to increased impedance. D-sorbitol has been used as an irrigating fluid during transurethral resection of the prostate, since it is considered to be a dielectric fluid. In order to determine whether D-sorbitol enhances the effect of RFA, RFA was performed by slowly injecting $3 \% \mathrm{D}$-sorbitol near the tip of the RFA needle. The maximum of the total injected volume of D-sorbitol was $20 \mathrm{ml}$ and RFA was terminated if the threshold of impedance was exceeded. RFA and D-sorbitol RFA were performed in 5 different parts of pig livers and dog livers in vivo. The total volumes of coagulation necrosis in the D-sorbitol RFA group were significantly higher compared with those in the RFA group. The total delivered energy in the D-sorbitol RFA group was also higher compared with that in the RFA group, due to the suppression of impedance elevation. No significant complications, such as bleeding or damage, were observed during the D-sorbitol RFA procedure in the in vivo model. In conclusion, RFA combined with D-sorbitol increases the total volume of coagulation necrosis through controlling impedance in the ablated liver and, therefore, D-sorbitol may be useful for the treatment of liver cancers.
\end{abstract}

Correspondence to: Dr Asahiro Morishita, Department of Gastroenterology and Neurology, Faculty of Medicine, Kagawa University, 1750-1 Ikenobe, Miki-cho, Kida-gun, Takamatsu, Kagawa 761-0793, Japan

E-mail: asahiro@med.kagawa-u.ac.jp

Abbreviations: RFA, radiofrequency ablation; PEI, percutaneous ethanol injection

Key words: D-sorbitol, radiofrequency ablation, liver cancers, impedance control, coagulation necrosis

\section{Introduction}

Radiofrequency ablation (RFA) has been accepted as a minimally invasive treatment for liver tumors (1) due to its tolerable side effects $(2,3)$. Although RFA is a major technique for the treatment of liver tumors, there is an important limitation of image-guided RFA, including higher local recurrence rate compared with that of surgical resection. It has been reported that the main cause of the higher local recurrence rate associated with RFA is inadequate volumes of tumor ablation (4-8). In order to improve these results, significant efforts have been focused on enhancing the therapeutic effects of RFA by combining it with other modalities, such as transcatheter arterial chemoembolization $(9,10)$, saline injection $(11,12)$, and percutaneous ethanol injection (PEI) (13). However, the local recurrence rate remains high.

D-sorbitol has been used as an irrigating fluid during transurethral prostate resection (14) and considered to be a dielectric fluid (15). During transurethral resection of the prostate, $\mathrm{D}$-sorbitol is used as lavage for removing blood and tissue fragments. If absorbed, D-sorbitol is metabolized to carbon dioxide and water via the fructose pathway, or excreted by the kidneys. To the best of our knowledge, thus far no experimental trial has demonstrated the efficacy of combination therapy using D-sorbitol and RFA.

In the present study, we attempted to demonstrate the efficacy of RFA with D-sorbitol in increasing the total volume of coagulation necrosis and analyzed the total delivered energy to elucidate the underlying mechanism.

\section{Materials and methods}

Animals and ethics. All animal experiments were performed in the Preclinical Animal Laboratory of Kagawa University (Kagawa, Japan). The protocol of this study was approved by the Institutional Animal Care and Use Committee of Kagawa University. Adult pig livers were purchased from Tokyo Shibaura Zoki K.K. (Tokyo, Japan). The 13-month-old dogs were purchased from Hokuzan Rabesu (Nagano, Japan) and maintained in a pathogen-free facility under controlled conditions with a 12-h light-dark cycle. 

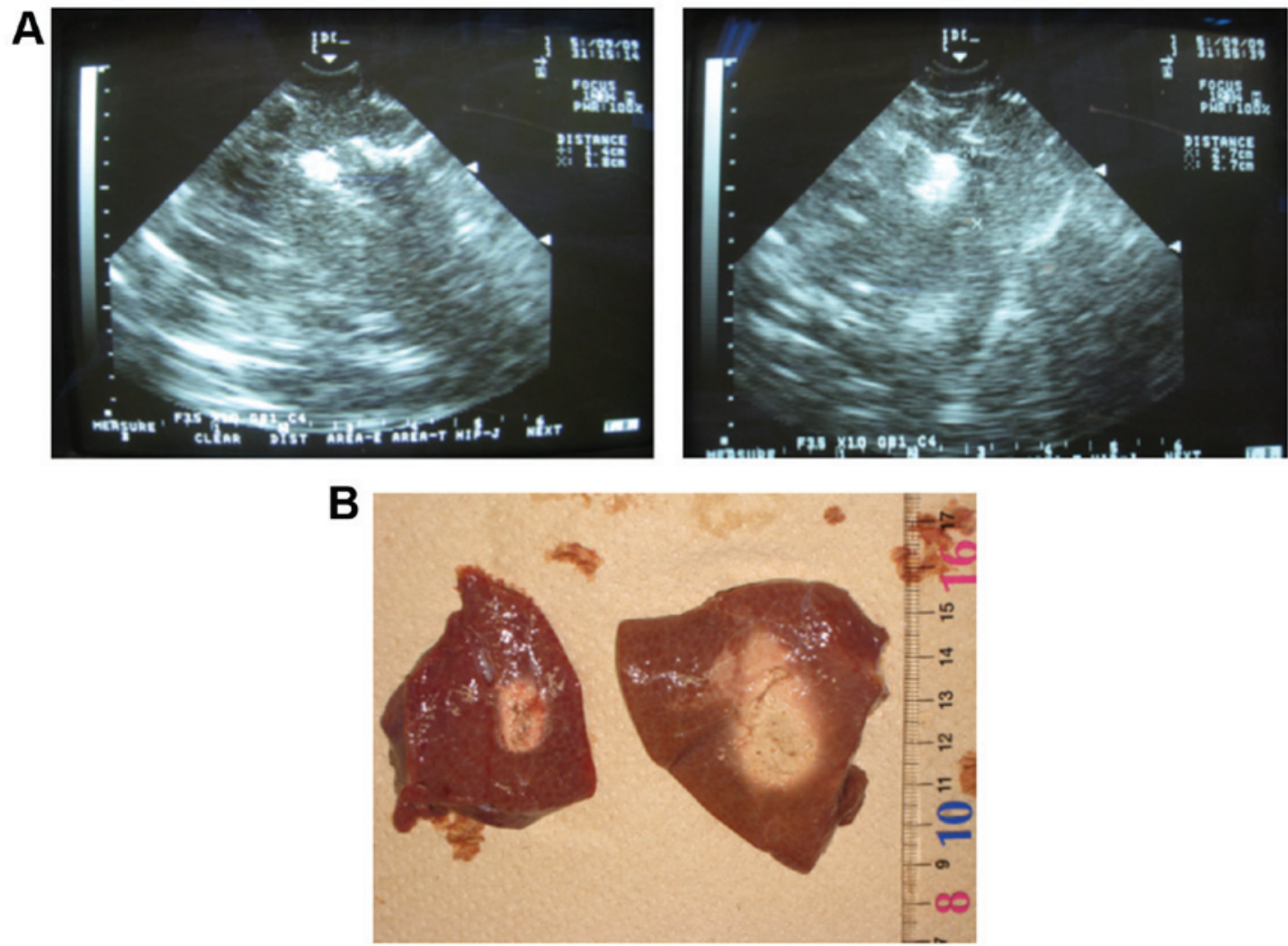

Figure 1. Effects of D-sorbitol RFA in pig livers. (A) RFA was performed without (left) and with D-sorbitol (right). (B) Macroscopic appearance following RFA (left) and D-sorbitol RFA (right). RFA, radiofrequency ablation.

Anesthesia and procedure. RFA and D-sorbitol RFA were performed under general anesthesia with intramuscular injection of ketamine $(10 \mathrm{mg} / \mathrm{kg})$ and xylazine hydrochloride (4 mg/kg). Intubation was performed 10-15 min later and the administration of $5 \%$ sevoflurane mixed with oxygen was maintained at 1-2 1/min. RFA was initiated after stable anesthesia was attained.

Equipment and D-sorbitol RFA procedure. D-sorbitol was purchased from Baxter Ltd. (Tokyo, Japan). D-sorbitol RFA was performed under real-time ultrasonographic guidance with a $3.5 \mathrm{MHz}$ sector probe (Power Vision 5000; Toshiba Medical, Tokyo, Japan) using the Cool-tip RF ablation system (Radionics, Burlington, MA, USA). For the D-sorbitol RFA treatment, a 16-gauge RFA needle was first inserted into the center of the tumor and a 18-gauge PEI needle was then introduced through the same hole of the attachment beside the echo probe. D-sorbitol $3 \%$ was slowly injected into the lesion through the side hole of the handpiece. The maximum total injected volume of D-sorbitol was $20 \mathrm{ml}$ and RFA was terminated if the threshold of impedance was exceeded. RFA was performed for $20 \mathrm{~W}$ in $2 \mathrm{~min}, 30 \mathrm{~W}$ in $2 \mathrm{~min}$ and $50 \mathrm{~W}$ until the end. The maximum allowable output power was $50 \mathrm{~W}$ under the impedance control injecting D-sorbitol.

Calculation of energy requirement for ablation and assessment of coagulation necrosis. The energy required for ablation was calculated as follows: Energy $(\mathrm{J})=$ Watt $(\mathrm{W}) \mathrm{x}$ duration of ablation (sec). Animal livers containing RFA-induced coagulation were sliced in the transverse plane perpendicular to the electrode tracks. The approximation volume of the whole coagulated necrosis area in $\mathrm{cm}^{3}$ was calculated as follows:

Whole coagulation volume $=4 / 3 \pi \times$ r1 x r2 $\times$ r3,

where r1, longest diameter/2; r2, shortest diameter/2; and r3, height $/ 2$, all measured in $\mathrm{cm}$. Two hepatologists with 10 years of clinical experience, who were blinded to the information regarding the RFA techniques used in the study, measured these parameters.

Stastistical analysis. All data are presented as means \pm standard deviation. Statistical significance was set at $\mathrm{P}<0.05$ for Student's unpaired t-tests.

\section{Results}

Comparison of coagulation between RFA andD-sorbitol-RFA in pig liver. RFA and D-sorbitol RFA were performed in 5 different parts of pig livers. All RFA techniques were performed using the Cool-tip RF system and $20 \mathrm{ml}$ of D-sorbitol was injected into the lesion through a 18-gauge PEI needle during RFA (Fig. 1A and $\mathrm{B}$, right). The results of the comparison of the volume of coagulation necrosis and the total delivered energy for inducing coagulation between the two groups are summarized in Table I. The volumes of coagulation necrosis in the D-sorbitol RFA group (Fig. 1A and B, right) were significantly higher compared with those in the RFA group (Fig. 1A and B, left). Of note, the total delivered energy in the D-sorbitol RFA group was also higher compared with that in the RFA group (Table I). 
Table I. Comparison of mean parameter values between the two groups in pig liver.

\begin{tabular}{lccc}
\hline Coagulation necrosis & RFA & D-sorbitol RFA & P-value \\
\hline Dmax (mm) & $14.4 \pm 1.14$ & $28.2 \pm 7.79$ & 0.0044 \\
Dmin (mm) & $11.4 \pm 0.89$ & $16 \pm 2.92$ & 0.0097 \\
Dv $(\mathrm{mm})$ & $10.8 \pm 0.84$ & $16.4 \pm 2.51$ & 0.0015 \\
Volume $\left(\mathrm{mm}^{3}\right)$ & $2,351.5 \pm 520.1$ & $10,821.1 \pm 6,580.3$ & 0.0209 \\
Dmax/Dmin & $1.33 \pm 0.05$ & $1.70 \pm 0.23$ & 0.0084 \\
Total delivered & $6,340 \pm 313.0$ & $14,800 \pm 3,898.7$ & 0.0013 \\
energy $(\mathrm{J})$ & & & \\
\end{tabular}

Values are presented as mean \pm standard deviation. RFA, radiofrequency ablation; Dmax, maximum diameter of ablation zone; Dmin, minimum diameter of ablation zone; Dv, vertical diameter of ablation zone. All P-values were statistically significant $(<0.05)$.

Table II. Comparison of mean parameter values between the two groups in dog liver.

\begin{tabular}{lccr}
\hline Coagulation necrosis & RFA & D-sorbitol RFA & P-value \\
\hline Dmax (mm) & $18.2 \pm 0.31$ & $32.1 \pm 2.97$ & 0.0013 \\
Dmin (mm) & $14.9 \pm 1.37$ & $24.1 \pm 0.36$ & 0.0004 \\
Dv (mm) & $14.7 \pm 1.3$ & $24.7 \pm 0.76$ & 0.0003 \\
Volume $\left(\mathrm{mm}^{3}\right)$ & $5,318.5 \pm 917.3$ & $25,418.2 \pm 1,545.6$ & $<0.0001$ \\
Dmax/Dmin & $1.23 \pm 0.12$ & $1.33 \pm 0.13$ & 0.3213 \\
Total delivered & $7,083.3 \pm 381.9$ & $17,333 \pm 3,214.6$ & 0.0054 \\
energy $(\mathrm{J})$ & & & \\
\hline
\end{tabular}

Values are presented as mean \pm standard deviation. RFA, radiofrequency ablation; Dmax, maximum diameter of ablation zone; Dmin, minimum diameter of ablation zone; Dv, vertical diameter of ablation zone.

Comparison of coagulation between RFA and D-sorbitol RFA in a dog model in vivo. The effect of D-sorbitol RFA was also examined in vivo using a dog model. The volumes of coagulation necrosis in the D-sorbitol RFA group were clearly higher compared with those in the RFA group in the dog model in vivo (Table II). In addition, the total delivered energy in the D-sorbitol RFA group was also higher compared with that in the RFA group (Table II). No significant complications, such as bleeding or damage, were observed during the procedures and 3 days after D-sorbitol RFA.

\section{Discussion}

RFA remains a promising technique for the local therapy of liver cancers, such as hepatocellular carcinoma and metastatic liver cancer $(6,16,17)$. However, the efficacy of this technique is limited by the size of coagulation necrosis, and only tumors sized $<3 \mathrm{~cm}$ are recommended for complete ablation, due to increased impedance. In order to control impedance during the ablation, D-sorbitol was used in combination with RFA therapy. During the D-sorbitol RFA procedure, impedance was regulated by the injection of $\mathrm{D}$-sorbitol and the total operative time was longer compared with that of RFA alone. Therefore, the size of the areas of induced coagulation necrosis was increased using D-sorbitol in animal livers. This suggests that the total volume of coagulation necrosis may be controlled by the injected volume of D-sorbitol suppressing impedance elevation in the ablated livers. It has also been reported that combination of RFA with other modalities enhances the therapeutic effects of RFA $(10,11,18)$. Kurokohchi et al demonstrated that ethanol-combined RFA increased the coagulated volumes 4-fold compared with those treated with RFA alone. In addition, the amount of injected ethanol and total energy were both required to increase coagulation necrosis (19). These studies support our finding that impedance control is key to the regulation of total energy, and D-sorbitol may increase the effectiveness of RFA treatment.

In conclusion, RFA combined with D-sorbitol increases the total volume of coagulation necrosis through controlling impedance in the ablated liver and, therefore, D-sorbitol may be useful for the treatment of liver cancers.

\section{References}

1. Decadt B and Siriwardena AK: Radiofrequency ablation of liver tumours: Systematic review. Lancet Oncol 5: 550-560, 2004.

2. Solbiati L, Goldberg SN, Ierace T, Livraghi T, Meloni F, Dellanoce M, Sironi S and Gazelle GS: Hepatic metastases: Percutaneous radio-frequency ablation with cooled-tip electrodes. Radiology 205: 367-373, 1997.

3. Solbiati L, Ierace T, Goldberg SN, Sironi S, Livraghi T, Fiocca R, Servadio G, Rizzatto G, Mueller PR, Del Maschio A, et al: Percutaneous US-guided radio-frequency tissue ablation of liver metastases: Treatment and follow-up in 16 patients. Radiology 202: 195-203, 1997.

4. Shiina S, Tateishi R, Arano T, Uchino K, Enooku K, Nakagawa H, Asaoka Y, Sato T, Masuzaki R, Kondo Y, et al: Radiofrequency ablation for hepatocellular carcinoma: 10-year outcome and prognostic factors. Am J Gastroenterol 107: 569-577, 2012.

5. Shiina S, Teratani T, Obi S, Sato S, Tateishi R, Fujishima T, Ishikawa T, Koike Y, Yoshida H, Kawabe T, et al: A randomized controlled trial of radiofrequency ablation with ethanol injection for small hepatocellular carcinoma. Gastroenterology 129: 122-130, 2005.

6. Curley SA, Izzo F, Delrio P, Ellis LM, Granchi J, Vallone P, Fiore F, Pignata S, Daniele B and Cremona F: Radiofrequency ablation of unresectable primary and metastatic hepatic malignancies: Results in 123 patients. Ann Surg 230: 1-8, 1999.

7. Lin SM, Lin CJ, Lin CC, Hsu CW and Chen YC: Radiofrequency ablation improves prognosis compared with ethanol injection for hepatocellular carcinoma $<$ or $=4 \mathrm{~cm}$. Gastroenterology 127 : 1714-1723, 2004.

8. Lencioni RA, Allgaier HP, Cioni D, Olschewski M, Deibert P, Crocetti L, Frings H, Laubenberger J, Zuber I, Blum HE, et al: Small hepatocellular carcinoma in cirrhosis: Randomized comparison of radio-frequency thermal ablation versus percutaneous ethanol injection. Radiology 228: 235-240, 2003.

9. Buscarini L, Buscarini E, Di Stasi M, Quaretti P and Zangrandi A: Percutaneous radiofrequency thermal ablation combined with transcatheter arterial embolization in the treatment of large hepatocellular carcinoma. Ultraschall Med 20: 47-53, 1999.

10. Yamasaki T, Kurokawa F, Shirahashi H, Kusano N, Hironaka K and Okita K: Percutaneous radiofrequency ablation therapy with combined angiography and computed tomography assistance for patients with hepatocellular carcinoma. Cancer 91: 1342-1348, 2001.

11. Livraghi T, Goldberg SN, Monti F, Bizzini A, Lazzaroni S, Meloni F, Pellicanò S, Solbiati L and Gazelle GS: Saline-enhanced radio-frequency tissue ablation in the treatment of liver metastases. Radiology 202: 205-210, 1997.

12. Honda N, Guo Q, Uchida H, Ohishi H and Hiasa Y: Percutaneous hot saline injection therapy for hepatic tumors: An alternative to percutaneous ethanol injection therapy. Radiology 190: 53-57, 1994. 
13. Kurokohchi K, Watanabe S, Masaki T, Hosomi N, Funaki T, Arima K, Yoshida S, Miyauchi Y and Kuriyama S: Combined use of percutaneous ethanol injection and radiofrequency ablation for the effective treatment of hepatocelluar carcinoma. Int J Oncol 21: 841-846, 2002.

14. Norlén H, Allgén LG, Bendz R and Wiklund A: Influence of various irrigation fluids on serum enzyme patterns following transurethral resection of the prostate. Scand J Urol Nephrol 20: 127-136, 1986.

15. Norlén H, Allgén LG and Wicksell B: Sorbitol concentrations in plasma in connection with transurethral resection of the prostate using sorbitol solution as an irrigating fluid. Scand J Urol Nephrol 20: 9-17, 1986.

16. Goldberg SN, Gazelle GS, Compton CC, Mueller PR and Tanabe KK: Treatment of intrahepatic malignancy with radiofrequency ablation: Radiologic-pathologic correlation. Cancer 88: 2452-2463, 2000.
17. Jiang HC, Liu LX, Piao DX, Xu J, Zheng M, Zhu AL, Qi SY, Zhang WH and Wu LF: Clinical short-term results of radiofrequency ablation in liver cancers. World J Gastroenterol 8: 624-630, 2002.

18. Kitamoto $M$, Imagawa $M$, Yamada $H$, Watanabe $C$, Sumioka $M$, Satoh O, Shimamoto M, Kodama M, Kimura S, Kishimoto K, et al: Radiofrequency ablation in the treatment of small hepatocellular carcinomas: Comparison of the radiofrequency effect with and without chemoembolization. AJR Am J Roentgenol 181: 997-1003, 2003.

19. Kurokohchi K, Watanabe S, Masaki T, Hosomi N, Miyauchi Y, Himoto T, Kimura Y, Nakai S, Deguchi A, Yoneyama H, et al: Comparison between combination therapy of percutaneous ethanol injection and radiofrequency ablation and radiofrequency ablation alone for patients with hepatocellular carcinoma. World J Gastroenterol 11: 1426-1432, 2005. 